\title{
Extensive intrafamilial and interfamilial phenotypic variation among patients with autosomal dominant retinal dystrophy and mutations in the human $\mathrm{RDS} /$ peripherin gene
}

\author{
E Apfelstedt-Sylla, M Theischen, K Rüther, H Wedemann, A Gal, E Zrenner
}

University Eye Hospital, Department of

Pathophysiology of Vision and

Neuro-ophthalmology, D-72076 Tuebingen, Germany

E Apfelstedt-Sylla

K Rüther

E Zrenner

University Eye Hospital, D-45122 Essen, Germany $M$ Theischen

Department of Human Genetics, Medical University, D-23538 Lübeck, Germany

H Wedemann

A Gal

Correspondence to:

Eckart Apfelstedt-Sylla, MD,

University Eye Hospital,

Schleichstrasse 12,

D-72076 Tuebingen,

Germany.

Accepted for publication 19 August 1994

\begin{abstract}
Clinical phenotypes of patients with mutations in the human RDS/peripherin gene are described. A 67-year-old woman, who carried a 1 base pair deletion in codon 307, presented with typical late onset autosomal dominant retinitis pigmentosa (RP). In another autosomal dominant pedigree, a nonsense mutation at codon 46 caused 'inverse' retinitis pigmentosa-like fundus changes associated with progressive cone-rod degeneration in a 58-year-old man, whereas his 40-year-old son presented with yellow deposits in the retinal pigment epithelial layer resembling a pattern dystrophy, and with moderately reduced rod and cone function, as determined by two colour dark adapted threshold perimetry and electroretinography. It is suggested that both clinical pictures within this latter family may represent manifestations of fundus flavimaculatus. The clinical data of the three patients provide further evidence for the remarkable variety of disease expression within and between families with mutations in the RDS/ peripherin gene. Currently, the most comprehensive statement could be that RDS/peripherin mutations are associated either with typical RP or with various forms of flecked retinal disease.
\end{abstract}

(Brf Ophthalmology 1995; 79: 28-34)

The gene for retinal degeneration slow (rds), a mouse model of human retinitis pigmentosa, was

RDS/peripherin codon 307 1-bp del
I

II

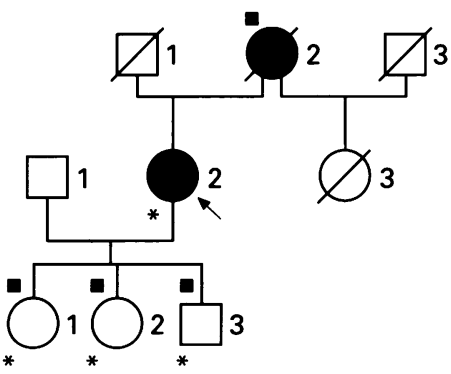

cloned in 1989.' The normal gene product is called RDS/peripherin, a protein which localises to the disc rim of photoreceptor outer segments, and which is considered to play a role in maintaining the structure of outer segment discs. ${ }^{23}$ In the human RDS/peripherin gene, ${ }^{+}$mutations were first identified in families with autosomal dominant retinitis pigmentosa (adRP, for review see Farrar $e t a l^{5}$ ). Subsequently, mutations were also found to be associated with fairly different phenotypes, such as macular dystrophy, ${ }^{6}$ pattern dystrophies of the retinal pigment epithelium (RPE), ${ }^{6-8}$ retinitis punctata albescens, ${ }^{9}$ and fundus flavimaculatus. ${ }^{8}$ In addition, clinically distinct entities such as retinitis pigmentosa, fundus flavimaculatus, and pattern dystrophy have recently been described to occur even within one family. ${ }^{8}$

Here we present clinical findings of three patients from two autosomal dominant pedigrees, which provide further evidence for wide phenotypic variation between and within families with RDS/peripherin mutations.

\section{Methods}

OPHTHALMIC EXAMINATION

For each proband, an extended questionnaire was completed with respect to age at onset of nightblindness, side vision impairment, glare sensitivity, and reading difficulties. Ophthalmic examination included distance visual acuities, slit-lamp examination, direct and indirect

RDS/peripherin Arg-46-stop

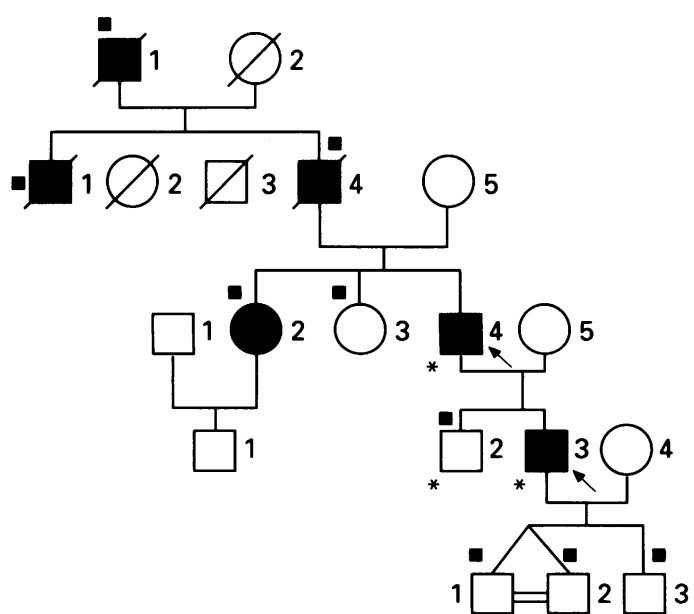

B 
funduscopy, fundus photography, colour vision test, kinetic or automated static perimetry, and two colour (500 and $656 \mathrm{~nm}$ ) dark adapted threshold perimetry (Tübinger perimeter), electroretinography (ERG), and, in one patient, fluorescein angiography. A detailed description of our methods has been published elsewhere. ${ }^{10}$ An extended ERG procedure was performed in cases of non-detectable ERG signals: in the scotopic state we presented a $10 \mathrm{~Hz}$ stimulus at standard flash intensity $\left(2.5 \mathrm{cds} / \mathrm{m}^{2}\right)$ and cut off

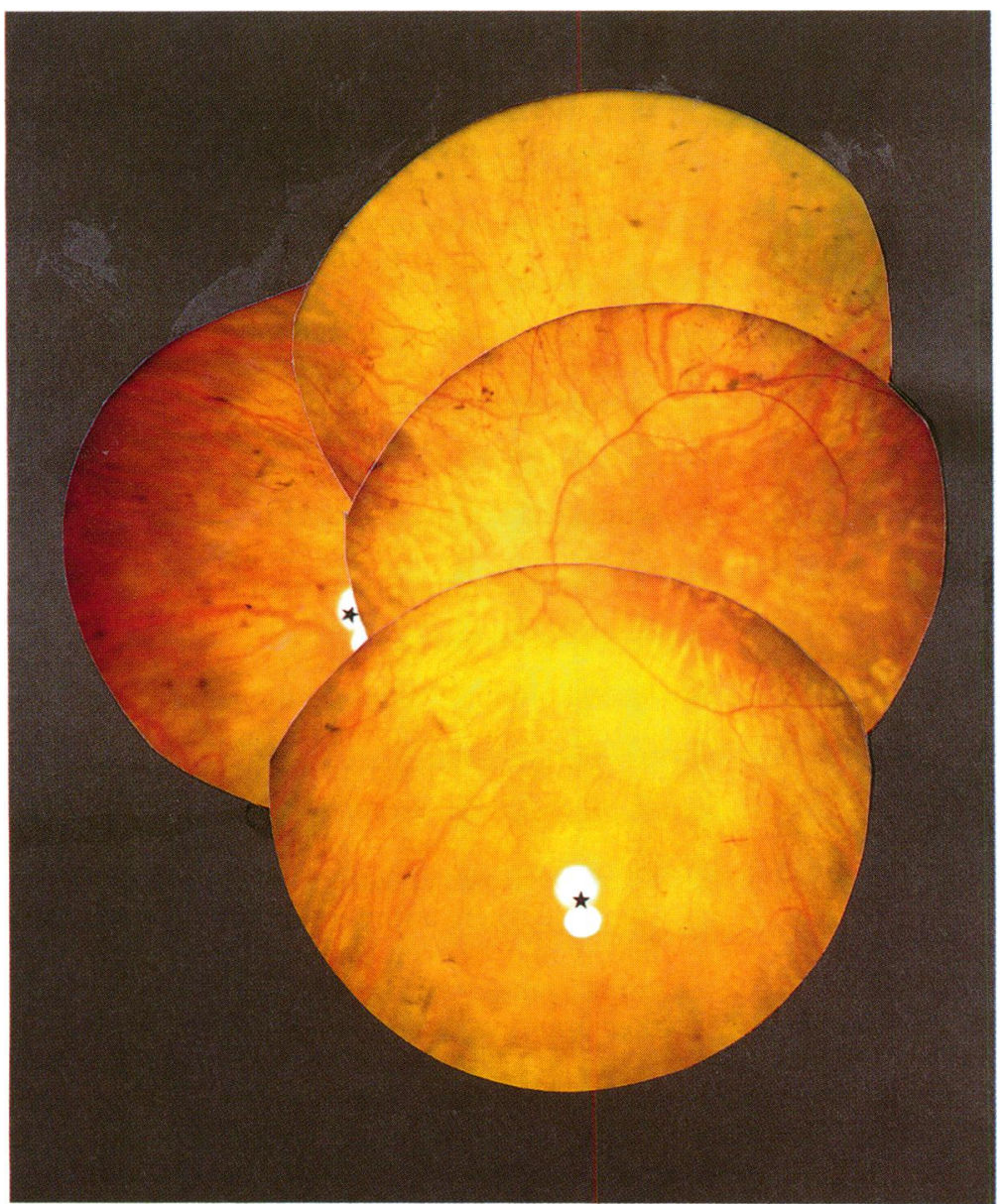

Fig $2 A$

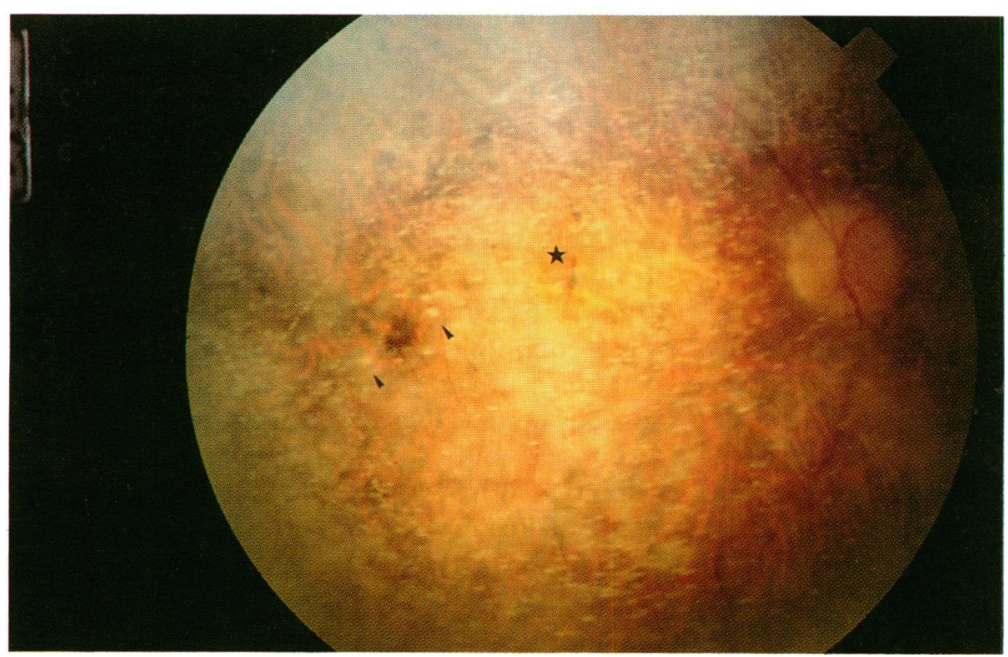

filters at 5 and $30 \mathrm{~Hz}$ and averaged 200 recordings at a time in order to detect remnant mixed $\mathrm{rod} /$ cone responses. In cases of non-recordable photopic amplitudes we applied a $30 \mathrm{~Hz}$ flicker stimulus of $3.6 \mathrm{cds} / \mathrm{m}^{2}$ with cut off filters set at 30 and $100 \mathrm{~Hz}$ and averaged 300 recordings.

\section{MOLECULAR GENETIC ANALYSIS}

The three exons of the RDS/peripherin gene were amplified by polymerase chain reaction (PCR) and analysed by single strand conformation polymorphism (SSCP) and heteroduplex analyses as described elsewhere. ${ }^{11}$

\section{Results}

\section{FAMILY 1 (SEE PEDIGREE IN FIG 1A)}

\section{Report of cases}

Individual I-2 was reported to have impaired night vision and visual acuity since about the age of 40 , and marked side vision problems since her seventh decade. By this time the diagnosis of RP was established by a local ophthalmologist.

Individuals III-1, 2, and 3 (ages 47, 37, and 33 , respectively), according to outside medical records, do not show any signs of retinal degeneration.

This 67-year-old woman (patient II-2) had noted a decrease of visual acuity and a constriction of her visual fields from the end of her fourth decade of life. Night vision problems did not become noticeable before the age of about 55 .

On examination, the visual acuity was $20 / 100$ right eye with a $-1 \mathrm{D}$ sphere and 5/150 left eye with $\mathrm{a}-1.5 \mathrm{D}$ sphere. There was an exotropia of the left eye. Biomicroscopy revealed a small posterior subcapsular cataract in both eyes as well as a trace of cells, a posterior detachment, and a synchisis scintillans (left eye only) of the vitreous. On funduscopy (Fig 2A), both eyes showed optic atrophy, severe vessel attenuation, diffuse peripheral RPE, and choriocapillaris atrophy and sparse bone spicule pigmentation. Within the central vascular arcades of both eyes there was some preserved pigment epithelium with atrophic foveal changes. Colour vision testing (right eye) revealed a marked tritan defect. Visual fields (Fig 3A) were constricted to

Figure 2 (A) Fundus (left eye) of patient II-2 (family 1, age 67), showing optic atrophy, attenuated vessels, confluent $R P E$ and choriocapillaris atrophy, sparse midperipheral bone spicule pigmentations, and foveal atrophy. ${ }^{\star}=$ artefacts. $(B)$ Posterior pole (right eye) of 58-year-old patient III-4 (family 2 ), showing optic atrophy, attenuated vessels, confluent RPE loss, some choriocapillaris atrophy, sparse bone spicule-like or clumpy intraretinal pigmentation, and single yellowish deposits at the RPE level (arrowheads). The foveola shows a tiny preserved patch of hyperpigmented RPE (asterisk). The multiple greyish flecks are caused by dense synchisis scintillans. (C) Right fundus of 40-year-old patient IV-3 (family 2), showing large yellowish plaques within the foveal $R P E$, small round spots surrounding the macula, and fuzzy flecks anterior to the upper vascular arcades. (D) Fluorescein angiogram (same eye) of IV-3, demonstrating a patterned blockade of choroidal fluorescence in the fovea, and, outside the fovea, multiple hyperfluorescent granules the result of retinal pigment epithelial defects. 


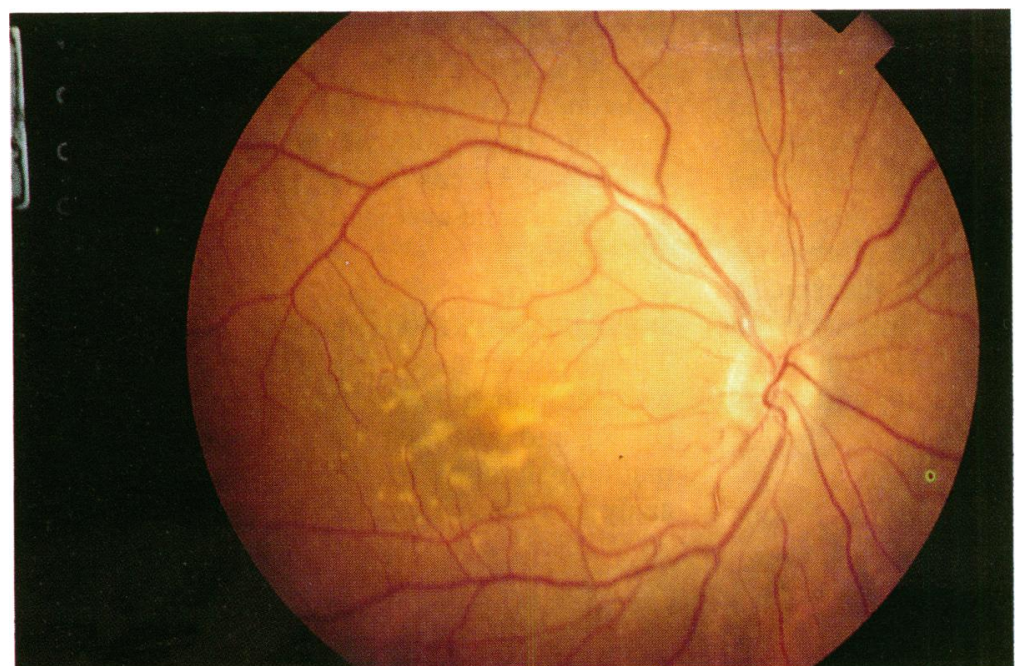

Fig 2C

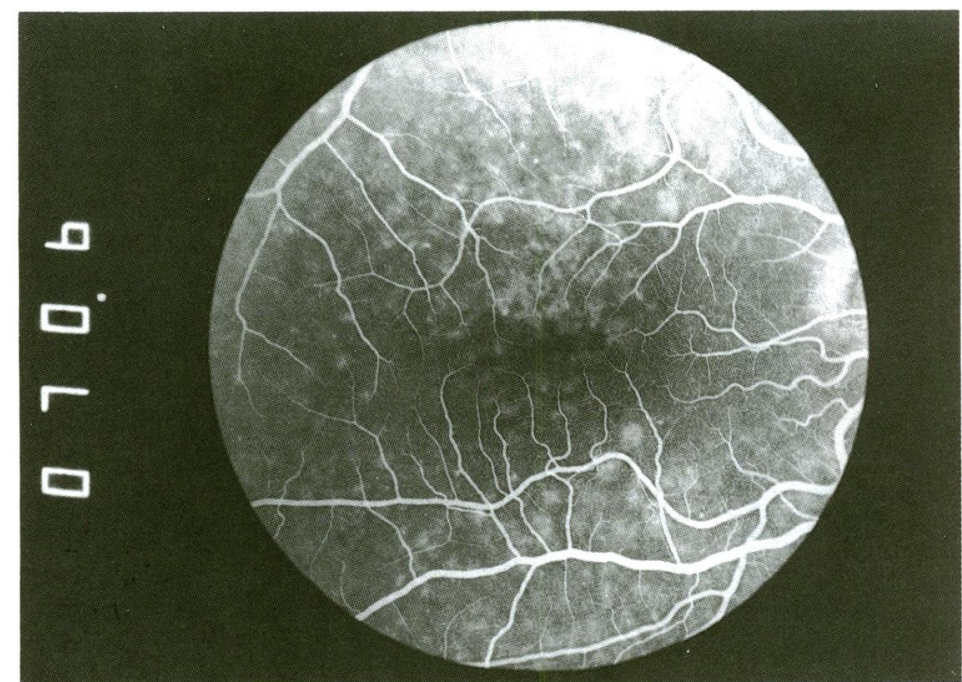

Fig $2 D$
FAMILY 2 (SEE PEDIGREE IN FIG 1B)

\section{Report of cases}

Individuals I-1 and II-1 were reported to have progressive loss of visual function from their midlives on. Detailed information was not available. Individual II-4 had experienced a marked loss of visual fields and reading acuity in his fifties, and was reported to have become blind at about the age of 70 . Individual III-2, a 57-yearold woman, was reported to have a macular degeneration. She lives abroad and was therefore not available for further investigation.

Proband III-4. This 58-year-old man first noted visual problems in mesopic environment and increased glare sensitivity in his second decade. Visual acuity and colour discrimination then deteriorated in his twenties. A loss of both night vision and visual fields became noticeable in his fourth decade of life. Since then he had experienced a progressive course of the disease finally leading on to an inability to read in his fifties.

At the age of 27, an ophthalmologist had established the diagnosis of Stargardt's macular dystrophy, but 20 years later, when examined in another clinic, he was looked upon as suffering from retinitis pigmentosa. By that time, some white flecks at the posterior poles were recorded as peculiar features of the fundus.

On our examination, visual acuity was $20 / 200$ right eye with $-0.5 \mathrm{cyl}$ axis $35^{\circ}$ and $1 / 200$ left eye with $-0 \cdot 25 \mathrm{sph}$. Biomicroscopy revealed clear lenses, but marked bilateral synchisis scintillans of the vitreous. On funduscopy (Fig 2B), he had optic atrophy, moderate vessel attenuation, and confluent RPE atrophy with some choroidal sclerosis extending from the posterior poles to the midperiphery, sparing only the foveola of the right eye where a tiny patch of hyperpigmented RPE could be seen. Within the atrophic RPE zones some bone spicule-like or clumpy pigmentations as well as single whitish flecks were scattered. The far fundus periphery appeared unchanged. Colour vision could not be tested because of poor vision. Kinetic perimetry (see Fig 4A) revealed a large central scotoma (left eye) and a ring scotoma (right eye), respectively, each extending to $30-40^{\circ}$ peripherally and leaving a central island of about $1^{\circ}$ diameter in the right eye only. Outer visual field borders were normal. On two colour dark adapted threshold perimetry of the right eye (Fig 5A), a regional degenerative pattern of both rods and cones was exhibited. There was an absolute scotoma corresponding to that found in photopic kinetic perimetry. Within the preserved temporal and nasal outer fields, rods detected the blue-green, and cones the red stimuli. Sensitivity losses to both stimuli ranged from 1.5 to $3 \log$ units. In the ERG (Fig 6) there was a roughly equal reduction of rod and cone function, with amplitudes reduced to $10-15 \%$ of normal mean values. Peak times of isolated rod responses and scotopic combined rod/cone responses were slightly delayed, and those of $30 \mathrm{~Hz}$ flicker as well as single white and red flash cone responses were grossly delayed. Oscillatory potentials were nonrecordable.

Proband IV-3. This 40-year-old man denied having any visual problems. On examination,

\begin{abstract}
altered at its carboxyl terminal end (for details see Grüning et $a l^{12}$ ). The 1 bp deletion was neither found in individuals III/1-3, nor in 160 unrelated patients with adRP.

Mutation screening in patient II-2 followed by direct sequencing revealed a 1 base pair (bp) periphen in codon 307 (exon III) of the RDS/ peripherin gene, leading to a shift in the reading
\end{abstract}


A
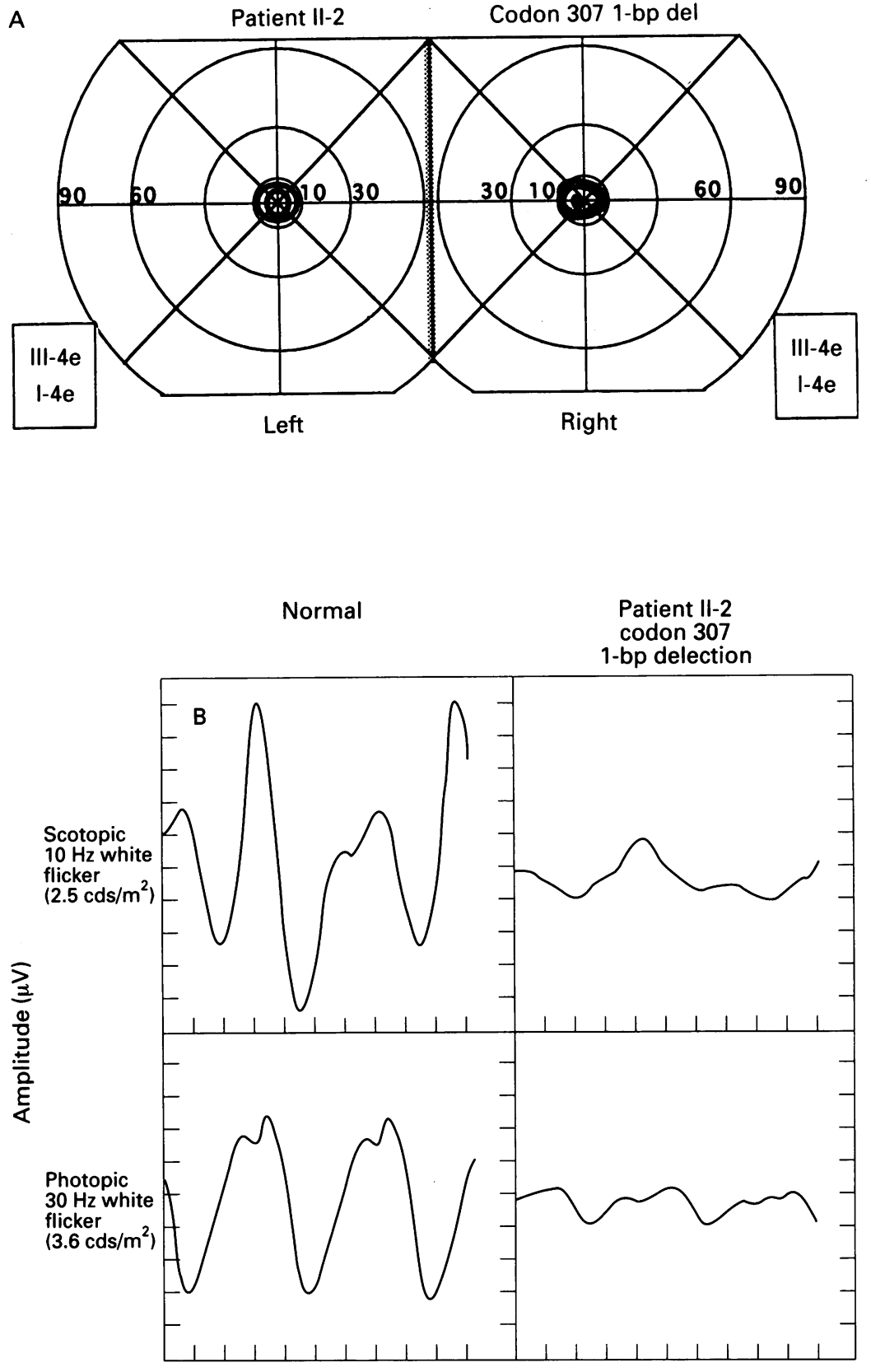

Figure 3 (A) Kinetic visual fields of patient II-2 (family 1), showing marked peripheral field loss. (B) ERG (right eye) of II-2, showing small residual responses to scotopic $10 \mathrm{~Hz}$ and photopic $30 \mathrm{~Hz}$ bright white flicker stimuli. Cone peak times following $30 \mathrm{~Hz}$ flicker stimulation are largely increased. Calibrations are $5 \mu \mathrm{V} /$ div and $15 \mathrm{~ms} /$ div (10 Hz flicker) and $2.5 \mu \mathrm{V} /$ div and $7.5 \mathrm{~ms} /$ div (30 $\mathrm{Hz}$ flicker), respectively.

visual acuity was $25 / 20$ with a correction of -0.5 cyl $\mathrm{A} 0^{\circ}$ in both eyes. Biomicroscopy revealed clear lenses. On funduscopy (Fig 2C), the optic discs and the retinal vessels appeared normal. However, multiple yellow-white, medium-sharp defined deposits varying in shape and size could be seen within the RPE layer. Large pisciform plaques were surrounding and partially invading the foveae. Smaller round deposits were scattered in the paramacular areas, and in several posterior midperipheral regions small linear flecks were arranged in a reticular pattern. No bone spicule pigmentations were seen. The equatorial and anterior fundus regions appeared normal. On fluorescein angiography of the right eye (Fig 2D) multiple hyperfluorescent spots appeared in the posterior pole, sparing only the fovea. They did not change during the transit nor stain in the late phases, thus being charac- teristic of RPE defects. In the fovea, there was a blockade of choroidal fluorescence corresponding to the large deposits seen on funduscopy, which showed a remote resemblance to a butterfly lesion. The desaturated Farnsworth D15 test revealed mild tritanomaly in both eyes. Static perimetry (Fig 4B), performed with the Tübinger automated perimeter, revealed normal outer field borders, but scattered paracentral scotoma in the inferior fields of both eyes extending from the inferior foveal edge to about $25^{\circ}$ peripherally. Marked sensitivity losses $(>25 \mathrm{~dB})$ predominated in the right eye which corresponded to the areas of major RPE defects detected by fluorescein angiography, whereas mild threshold elevations (>5-10 dB) were found in the left eye. Two colour dark adapted static perimetry along the vertical meridian of the right eye (Fig 5B) revealed a more widespread area of subnormal rod and cone sensitivity, covering the central $30^{\circ}$ superiorly and the central $40^{\circ}$ inferiorly. Rod sensitivity (to $500 \mathrm{~nm}$ ) was reduced by about $0.5 \log$ units at $30-40^{\circ}$ eccentricity and by $1-1.5 \log$ units within the central $20^{\circ}$. Cone sensitivity to $656 \mathrm{~nm}$, however, was still within normal limits or near normal between $6^{\circ}$ inferiorly and $10^{\circ}$ superiorly. Cone threshold elevations in the remaining loci varied between 0.5 and $1.5 \mathrm{log}$ units. Sensitivity differences confirmed a roughly equal functional loss of rods and cones with a slight preponderance of rod impairment in the perifoveal regions. In the ERG (Fig 6), isolated rod signals, scotopic mixed $\mathrm{rod} /$ cone amplitudes, oscillatory potentials, and light adapted $30 \mathrm{~Hz}$ flicker and single flash cone amplitudes were all reduced to about one third of normal mean values. Peak times of rod and cone signals were within the normal range.

Persons III-3 and IV-2 both have no subjective visual complaints and do not show any signs of retinal disease. The offspring of IV-3, individuals V-1 to 3 have not complained of visual problems and currently are not available for ocular examination.

\section{Molecular genetic findings}

DNA samples of III-4 and IV-3 showed a particular SSCP pattern for exon I of the RDS/ peripherin gene. Direct sequencing revealed a C-to-T transition (CGA for TGA) at codon 46 creating an in frame translation stop signal (for details see Meins et $a^{13}$ ).

\section{Discussion}

We studied the clinical expression of RDS/ peripherin mutations in three individuals from two different pedigrees. Our data provide further evidence for the highly varying phenotypic expression of RDS/peripherin gene defects between and within families. In one of our patients, who carries a 1 bp deletion in codon 307 , the phenotype is a late onset adRP with typical features like disc pallor, vessel attenuation, bone spicule pigment deposits, and peripheral visual field loss. However, the widespread choriocapillaris atrophy observed is not a constant finding in RP. It may be concluded from the history of subjective symptoms in both the 
A

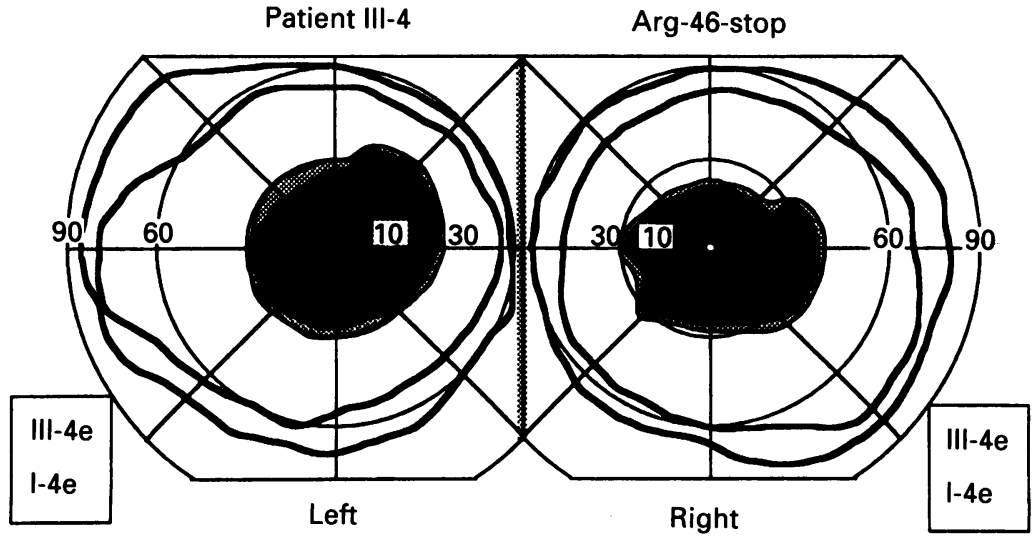

B
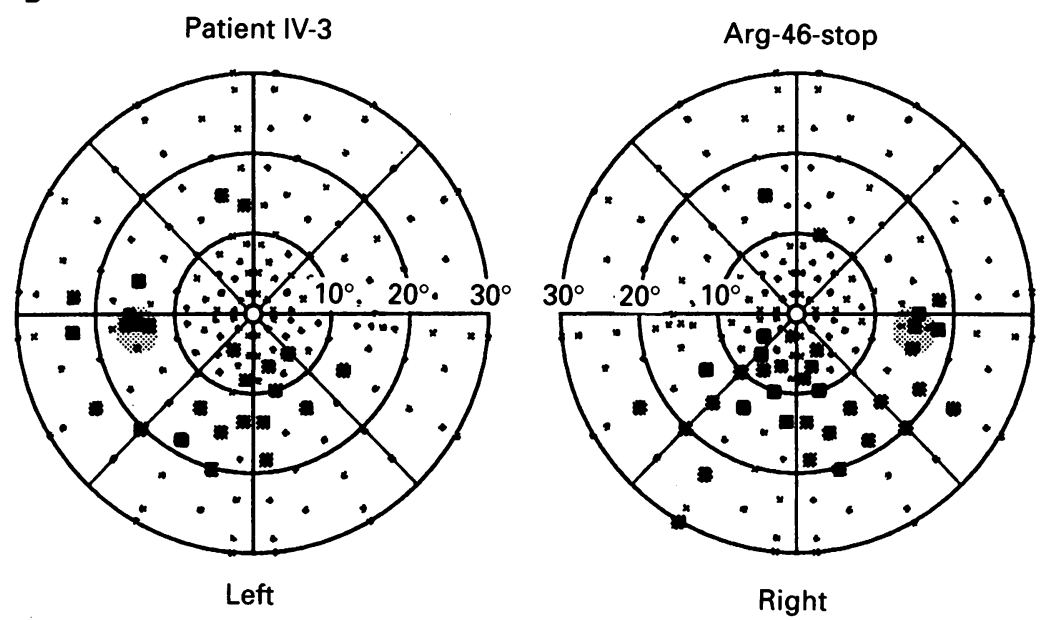

$30^{\circ}$ visual fields

(Tübinger automated perimeter)

Absolute scotoma Relative scotoma

Figure 4 (A) Kinetic visual fields of patient III-4 (family 2). There is a large ring scotoma in the right eye and a large central scotoma of the left eye respectively. Outer field borders are normal. (B) Static $30^{\circ}$ visual fields of IV-3 (family 2 ) showing inferior paracentral scotomas.

patient and her affected mother that rod function loss occurred comparatively late and did not substantially exceed impairment of cone function, thus suggesting a 'type 2 ' RP. ${ }^{14}$ This is not unexpected, because RDS/peripherin is expressed both in rods and cones, and mutations can therefore affect both photoreceptor types. Comparable phenotypes with rather mild disease have been described in other patients with RDS/ peripherin mutations. ${ }^{68}$ The $1 \mathrm{bp}$ deletion causes a shift of the reading frame and thereby a substantial alteration of the carboxyl terminal amino acid sequence with a premature termination of translation at codon 323. This domain of the molecule is not conserved among different species, ${ }^{4}$ and its precise function is unknown.

The retinal disorders found in our patients with the Arg-46-stop mutation are more difficult to classify. One 40-year-old man (IV-3) shows yellow-white deposits at the RPE layer, which are most striking in the fovea of both eyes. An accumulation of yellowish lipofuscin-like material in the foveal RPE is a characteristic of autosomal dominant pattern dystrophies of the RPE. ${ }^{15-18}$ Nichols $e t a l^{7}$ found that patients with a missense mutation in codon 167 of the RDS/ peripherin gene had butterfly-shaped pattern dystrophy. The fundus appearance of one of their patients does not differ substantially from that found in IV-3. As a rule however, individuals with pattern dystrophies have normal ERGs and so did the patients with the codon 167 mutation. In contrast, our proband had clearly abnormal ERG results, a finding which has been only sporadically described in pattern dystrophies. ${ }^{1617}$ In addition, IV-3 has moderate but widespread rod and cone sensitivity loss in dark adapted threshold perimetry, a finding which would be unexpected in macular pattern dystrophies. Gass ${ }^{18}$ pointed out that the funduscopic findings in fundus flavimaculatus, a diffuse condition, may in some cases be hardly distinguishable from those in pattern dystrophies.

The older patient (III-4) with the Arg-46-stop mutation presents with RP-like fundus changes and, with respect to the sequence and pattern of his visual function loss, could be considered as having cone-rod dystrophy (CRD). Patients with CRD differ from those having typical RP by complaining of visual acuity loss rather than of nightblindness, by having pigmentary changes that are most prominent within the macular region and not in the midperipheral fundus, and by showing cone ERG impairment that is greater than or equal to rod impairment. ${ }^{19} 20$ On the other hand, cone-rod dystrophies tend to have early onset with severe visual impairment even at younger ages, and this obviously does not hold for patient III-4. In addition it is worth mentioning that at earlier stages of the disease he had a 'flecked retina', which is not a feature of CRD, and was diagnosed as having Stargardt's macular dystrophy. Therefore we suggest that the conditions of both patients are disparate manifestations of fundus flavimaculatus. The term 'fundus flavimaculatus' was introduced in 1962 by Franceschetti ${ }^{21}$ to describe the fundus of patients with linear and round, deep yellow, fleck-like deposits in the deeper retinal layers. Later it has been suggested that Stargardt dystrophy and fundus flavimaculatus are the same entity. ${ }^{22-25}$ Typical fundus flavimaculatus is a progressive autosomal recessive disease, which may or may not be associated with atrophic macular lesions and consecutive decrease of central vision; the ERG is usually normal or shows slight cone function impairment. ${ }^{22-25}$ However, fundus flavimaculatus rarely may evolve into a condition including disc pallor, retinal arteriolar attenuation, pigmentary deposits, diffuse pigment epithelial or retinochoroidal atrophy, disappearance of the yellow flecks, and marked cone and rod ERG impairment, thus mimicking a form of retinitis pigmentosa. ${ }^{23-25}$ In addition, there have been a few reports on autosomal dominant inheritance of fundus flavimaculatus. ${ }^{22} 24$ Krill $^{24}$ observed considerable variation among affected members of autosomal dominant pedigrees, with the majority of patients showing a mild form and single members suffering from severe progressive cone-rod disease. This is also true for the family with the Arg-46-stop mutation presented here. We therefore believe that 'fundus flavimaculatus' is the most appropriate term to describe the clinical phenotype of this family. 
Figure 5 Dark adapted two colour threshold profiles in normal observers (upper curves, mean $2 S D$ ) and in patients III-4 $(A)$ and IV-3 (B) of family 2 (lower curves). Top: sensitivities to $500 \mathrm{~nm}$, middle: sensitivities to $656 \mathrm{~nm}$, bottom: sensitivity differences between the two stimuli. In both patients, there is a regional type of

photoreceptor sensitivity loss, normal or near-normal sensitivity differences indicate a roughly equivalent rod and cone function loss.

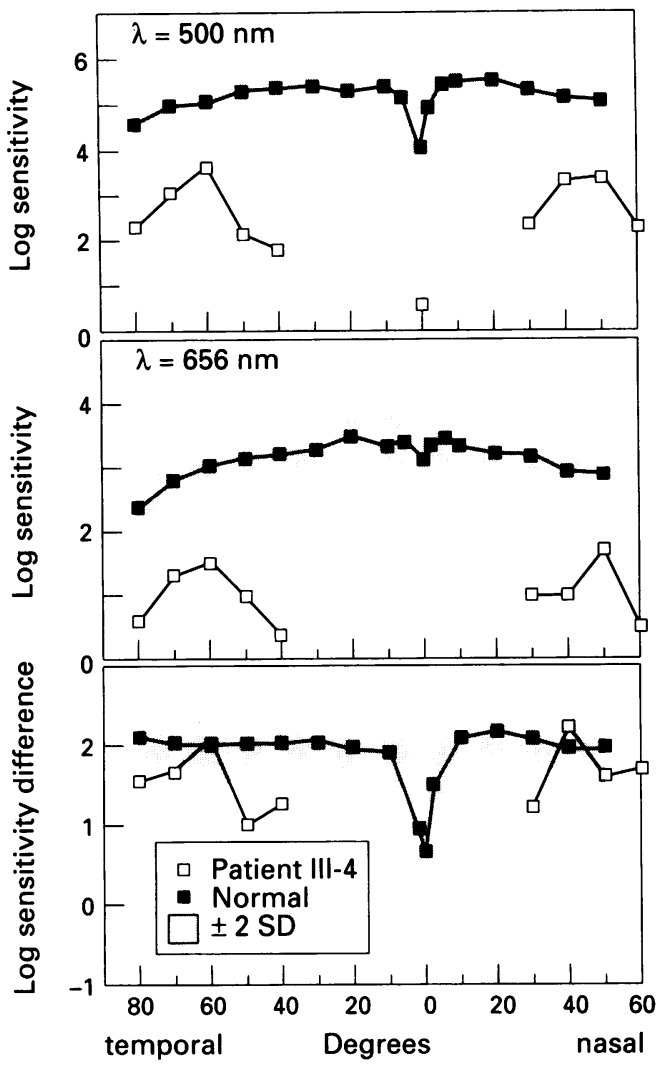

B

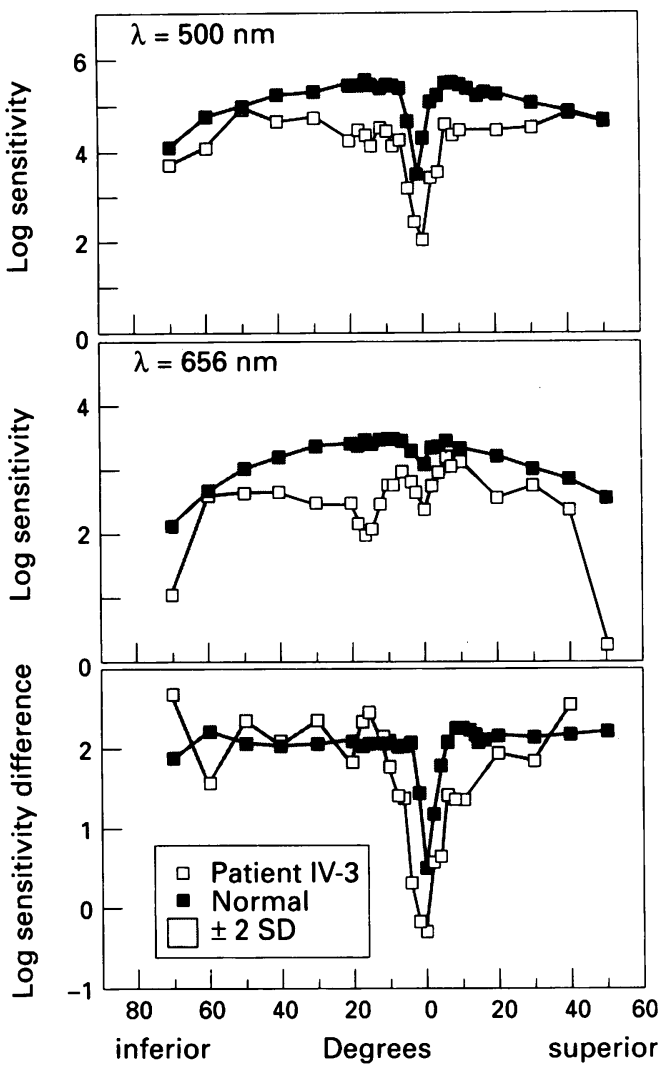

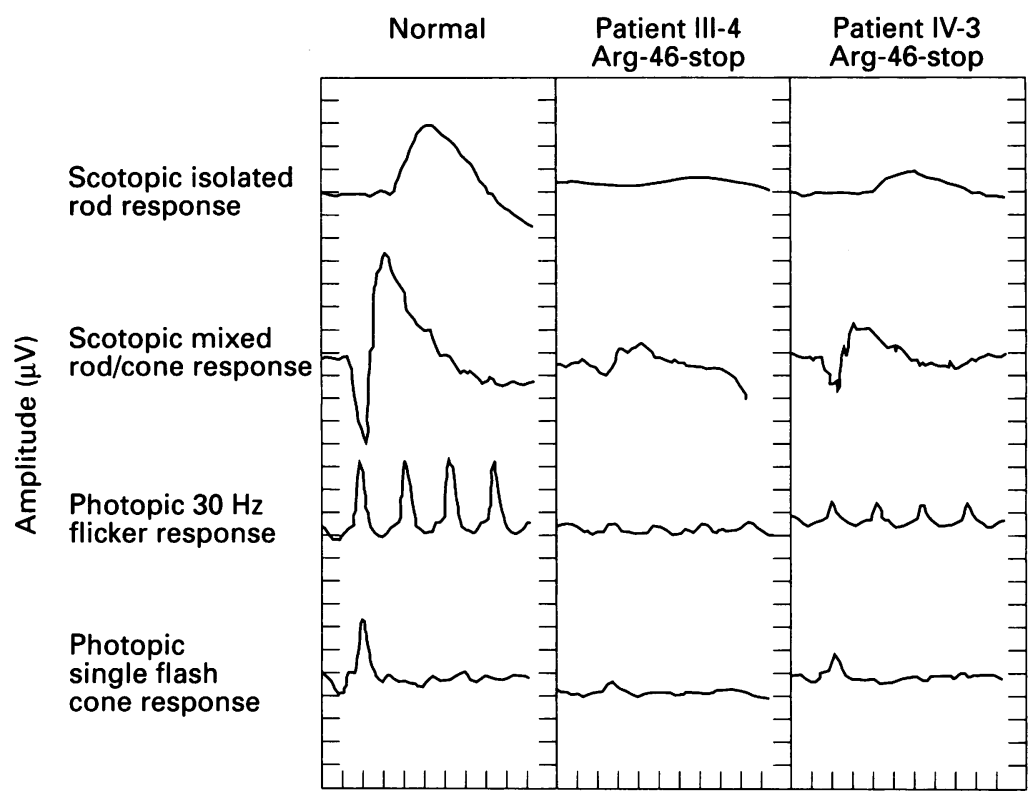

Figure 6 ERG rod and cone responses in individuals III-4 (age 58), and IV-3 (age 40) of family 2, compared with those of a normal subject approximating the median of normal values (left). In both patients there is an equal reduction of rod and cone amplitudes. In III-4, scotopic peak times are slightly increased, photopic cone responses are grossly delayed. In IV-3, scotopic and photopic peak times are normal. Calibrations (top to bottom) are: $50 \mu \mathrm{Vldiv}$ and $20 \mathrm{~ms} / \mathrm{div}$ in traces 1 and 2 , and $50 \mu V / d i v$ and $15 \mathrm{~ms} /$ div in traces 3 and 4 , respectively.

Similar findings - that is, a flecked retina in a younger patient and widespread photoreceptor function loss in her father, have been described in a family with a $2 \mathrm{bp}$ deletion in codon 25 of the RDS/peripherin gene. ${ }^{9}$ The authors, however, used the term 'retinitis punctata albescens' to describe that condition.

$\mathrm{RDS} /$ peripherin is believed to play a role in maintaining the structure of outer segment discs. ${ }^{23}$ How can mutations in this protein compromise photoreceptor outer segment stability? In mice heterozygous for the rds mutation there should be a reduced amount of peripherin in the photoreceptor membrane (null allele). Apparently this insufficiency causes ballooned, swollen, and distorted rod outer segments. ${ }^{27}$ A similar pathomechanism may act in human RDS/peripherin null alleles. Thus far phenotypes of two presumed null mutations have been described in detail: one nonsense mutation at codon 258 , presenting as adult onset vitelliform macular dystrophy, ${ }^{6}$ and a frameshift mutation at codon 25 which creates a translation stop at codon 42 and which is associated with 'retinitis punctata albescens'.9 We suggest that the Arg-46-stop mutation described herein also represents a null allele, because the short length of the encoded protein should lead to an instability of the gene product. Thus one can consider fundus flavimaculatus to be another human phenotype comparable with rds in mice. The Arg-46-stop mutation has been previously reported to be associated with adRP. ${ }^{28}$ Detailed clinical data, however, have not been published. The extensive clinical variety of null allele phenotypes is surprising and unexplained. Additional genetic as well as non-genetic factors may play a role, which could be further studied once larger numbers of genetically characterised patients are available for examination.

This study was supported by grants Ru 457/1-1 and Ga 210/5-4 of the Deutsche Forschungsgemeinschaft (DFG). We thank Ms K Endress and Ms J Isensee for their expert technical assistance, and the patients involved in this study for their kind cooperation.

1 Travis GH, Brennan MB, Danielson PE, Kozak CA, Sutcliffe JG. Identification of a photoreceptor-specific mRNA encoded by the gene responsible for retinal degeneration slow (rds). Nature $1989 \cdot 338: 70-3$.

2 Connell G, Molday RS. Molecular cloning, primary structure, and orientation of the vertebrate photoreceptor cell protein peripherin in the rod outer segment disc membrane. Biochemistry 1990; 29: 4691-8. 
3 Connell G, Bascom R, Molday L, Reid D, McInnes RR, Molday RS. Photoreceptor peripherin is the normal product of the gene responsible for retinal degeneration in the rds mouse. Proc Natl Acad Sci USA 1991; 88: 723-6.

4 Travis GH, Christerson L, Danielson PE, Klisak I, Sparkes RS, Hahn LB, et al. The human retinal degeneration slow (RDS) gene: chromosome assignment and structure of the mRNA. Genomics 1991; 10: 733-9.

5 Farrar GJ, Jordan SA, Kumar-Singh R, Inglehearn CF, Gal A, Greggory C, et al. Extensive genetic heterogeneity in autosomal dominant retinitis pigmentosa. In: Hollyfield JG Anderson RE, La Vail MM, eds. Retinal degeneration. New
York: Plenum Press, 1993; 63-77.

York: Pler

Wells J, Wroblewski J, Keen J, Inglehearn C, Jubb C Eckstein A, et al. Mutations in the human retinal degeneration slow (RDS) gene can cause either retinitis pigmentosa or macular dystrophy. Nature Genet 1993; 3: 213-8.

7 Nichols BE, Sheffield VC, Vandenburgh K, Drack AV, Kimura AE, Stone EM. Butterfly-shaped pigment dystrophy of the fovea caused by a point mutation in codon 167 of the RDS gene. Nature Genet 1993; 3: 202-7.

8 Weleber RG, Carr RE, Murphey WH, Sheffield VC, Stone EM. Phenotypic variation including retinitis pigmentosa, pattern dystrophy, and fundus flavimaculatus in a single family with a deletion of codon 153 and 154 of the peripherin/RDS gene. Arch Ophthalmol 1993; 111: peripherin

9 Kajiwara K, Sandberg MA, Berson EL, Dryja TP. A null mutation in the human peripherin/RDS gene in a family with autosomal dominant retinitis punctata albescens. Nature Genet 1993; 3: 208-12.

10 Apfelstedt-Sylla E, Kunisch M, Horn M, Rüther K, Gerding $\mathrm{H}, \mathrm{Gal} \mathrm{A}$, Zrenner E. Ocular findings in a family with autosomal dominant retinitis pigmentosa and a frameshif mutation altering the carboxyl terminal sequence of rhodopsin. Brf Ophthalmol 1993; 77: 495-501.

11 Bunge S, Wedemann H, David D, Terwilliger DJ, van den Born LI, Aulehla-Scholz C, et al. Molecular analysis and genetic mapping of the rhodopsin gene in families with genetic mapping of the rhodopsin gene in families with
autosomal dominant retinitis pigmentosa. Genomics 1993; 17: $230-3$.

12 Grüning G, Millan JM, Meins $M$, Beneyto $M$, Caballero $M$, Apfelstedt-Sylla $E$, et al. Mutation in the human peripherin RDS gene associated with autosomal dominant retinitis pigmentosa. Hum Mutat 1994; 3: 321-3.

13 Meins M, Grüning G, Blankennagel A, Krastel H, Reck B, Fuchs S, et al. Heterozygous 'null allele' mutation in the human

14 Massof RW, Finkelstein D. Two forms of autosomal dominant primary retinitis pigmentosa. Doc Ophthalmol 1981; 51: 289-346.

15 Deutman AF, van Blommestein JDA, Henkes HE Waardenburg PJ, Solleveld-van Driest E. Butterfly-shaped pigment dystrophy of the fovea. Arch Ophthalmol 1970;83: 558-69.

16 Watzke RC, Folk JC, Lang RM. Pattern dystrophy of the retinal pigment epithelium. Ophthalmology 1982; 89: $1400-6$.

17 Cortin P, Archer D, Maumenee IH, Feiock K, Speros P. A patterned macular dystrophy with yellow plaques and A patterned macular dystrophy with yellow plaques
atrophic changes. Br O Ophthalmol 1980; 64: 127-34.

18 Gass JDM. Stereoscopic atlas of macular diseases. St Louis: Mosby, 1987; 246-57.

19 Berson EL, Gouras P, Gunkel RD. Progressive cone-rod degeneration. Arch Ophthalmol 1968; 80: 68-76.

20 Yagasaki K, Jacobson SG. Cone-rod dystrophy: phenotypic diversity by retinal function testing. Arch Ophthalmol 1989; 107: 701-8.

21 Franceschetti A. Über tapetoretinale Degenerationen im Kindesalter. In: Sauter $\mathrm{H}$, ed. Entwicklung und Fortschrift in der Augenheilkunde, Stuttgart: Ferdinand Enke, 1963; $107-20$.

22 Franceschetti A, Francois J, Babel J. Fundus flavimaculatus: chorioretinal heredodegenerations with central preponderchorioretinal heredodegenerations with central preponderance. Macular degenerations: infantile and juvenile forms
(Stargardt's disease). In: Franceschetti A, Francois J, Babel (Stargardt's disease). In: Franceschetti A, Francois J, Babe J, eds. Chorioretinal heredodegener.

23 Fishman GA. Fundus flavimaculatus. Arch Ophthalmol 1976; 94: 2061-7.

24 Krill AE. Flecked retina diseases. In: Krill AE, ed (with assistance of Archer DB). Krill's hereditary retinal and choroidal diseases: Clinical characteristics. New York: Harper \& Row, 1977: 739-824.

25 Blacharski P. Fundus flavimaculatus. In: Newsome DA, ed. Retinal dystrophies and degenerations. New York: Raven Press, 1988: 135-59.

26 Cibis GW, Morey M, Harris DJ. Dominantly inherited macular dystrophy with flecks (Stargardt). Arch Ophthalmol macular dystrophy

27 Hawkins RK, Jansen HG, Sanyal S. Development and degeneration of retina in rds mutant mice: photoreceptor abnormalities in the heterozygotes. Exp Eye Res 1985; 41 701-20.

28 Stone EM, Vandenburgh SK, Kimura AE, Lam BL, Fishman GA, Heckenlively JR, et al. Novel mutations in the peripherin (rds) and rhodopsin genes associated with autosomal dominant retinitis pigmentosa (ADRP). Invest Ophthalmol Vis Sci 1993; 34 (suppl): 1149. 